\title{
A new cancer on the block: Tuberous Sclerosis Associated Renal Cell Carcinoma
}

\begin{tabular}{|c|c|}
\hline Journal: & Journal of Clinical Urology \\
\hline Manuscript ID & URO-19-0078.R1 \\
\hline Manuscript Type: & Case Review \\
\hline $\begin{array}{r}\text { Date Submitted by the } \\
\text { Author: }\end{array}$ & 22-Oct-2019 \\
\hline Complete List of Authors: & $\begin{array}{l}\text { Cui, Helen; Oxford University Hospitals NHS Foundation Trust, Urology } \\
\text { Department } \\
\text { Verrill, Clare; Oxford University Hospitals NHS Foundation Trust, } \\
\text { Pathology } \\
\text { Sullivan, Mark; Oxford University Hospitals NHS Foundation Trust, } \\
\text { Urology Department }\end{array}$ \\
\hline Keywords: & $\begin{array}{l}\text { Oncology (Renal), Basic Science, Education, Oncology, Other } \\
\text { investigation }\end{array}$ \\
\hline Abstract: & $\begin{array}{l}\text { Purpose } \\
\text { To present the first reported case of a renal tumour classified as } \\
\text { Tuberous Sclerosis Complex (TSC)-associated Renal Cell Carcinoma } \\
\text { (RCC) in the UK and discuss its clinical implications. } \\
\text { Case Report } \\
\text { A female, aged 65, with TSC was found on surveillance imaging to have } \\
\text { interval growth of multiple right renal tumours up to } 19 \mathrm{~mm} \text {. Right partial } \\
\text { nephrectomy was performed. Histology showed multiple tiny } \\
\text { angiomyolipomas and a } 20 \mathrm{~mm} \text { tumour classified as TSC-associated } \\
\text { RCC. These tumour cells showed abundant clear cytoplasm with a } \\
\text { branched elongated arranged encircled in dense smooth muscle stroma. } \\
\text { Literature Review } \\
\text { RCC in patients with TSC is rare, occurring in approximately } 4 \% \text { of } \\
\text { cases. TSC-associated RCC is a relatively new histological entity, having } \\
\text { previously been described as clear cell or chromophobe-like, with only } \\
\text { one published case series from the US. These tumours have three } \\
\text { histological entities which are distinct from all other RCC classifications. } \\
\text { Based on case series, TSC-associated RCC tends to occur more often in } \\
\text { females, present a younger age, have multiple tumours, and tend to } \\
\text { show an indolent course, although metastases have been reported. } \\
\text { Learning points } \\
\text { Patients with TSC can develop RCC, though the risk is thought to be no } \\
\text { higher than for sporadic RCC. Given the limited literature, more evidence } \\
\text { is required to help predict the future behaviour of these tumours. } \\
\text { Level of evidence = } 5\end{array}$ \\
\hline
\end{tabular}


2

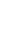

\section{SCHOLARONE ${ }^{m}$ Manuscripts}




\section{Declarations}

Conflicting interests: All authors report no conflicting interests for this work.

Funding: No funding was received for this work.

Informed consent: Written informed consent from the patient was obtained for publication of this case report including images and information.

Ethical approval: Written informed consent from the patient was obtained.

Guarantor: HWC

Contributorship: HWC and MS obtained the details of the case review, HWC researched the literature and wrote the case review, CV reviewed the histological images. All authors reviewed and edited the manuscript and approved the final version of the manuscript.

Acknowledgements: No acknowledgements. 


\section{Case Summary}

Patient SP, a 65-year-old lady, with known Tuberous Sclerosis Complex (TSC) was diagnosed with multiple renal tumours in her right kidney and underwent right open partial nephrectomy. She had a past medical history of TSC (genotype unknown), hypothyroidism, previous deep vein thrombosis and peripheral arterial disease. Her renal function was within normal range with a serum creatinine of $71 \mu \mathrm{mol} / \mathrm{L}$ and eGFR of $80 \mathrm{ml} / \mathrm{min} / 1.73 \mathrm{~m}^{2}$. After confirmation of TSC approximately 40 years ago, she had mainly skin manifestations including hypomelanotic macules on the legs, facial angiofibromas on the nose, and ungual fibromas. Renal angiomyolipomas (AML) and renal cysts were picked up incidentally on ultrasound scan around 20 years ago which have not previously required intervention. She entered imaging surveillance at our institution since 2015. At this point she had AMLs in both kidneys, each $11 \mathrm{~mm}$ or less. However, in the year preceding surgery, the lower pole lesion had increased in size from $10 \mathrm{~mm}$ to $19 \mathrm{~mm}$ with enhancement suspicious for renal cell carcinoma. There was a further suspicious right interpolar cyst that contained a solid nodular component.

Subsequently, a partial nephrectomy was performed through a supra-12th rib loin incision and a total of three renal tumours were excised: a right upper pole cyst; a small mid-pole cystic lesion and the lower pole tumour suspicious for RCC. She had an uncomplicated post-operative course.

Histology from her partial nephrectomy showed a benign $20 \mathrm{~mm}$ angiomyolipoma removed from the upper pole with numerous mini angiomyolipomas also present. The other malignant lesions were a $4 \mathrm{~mm}$ solid nodule and a $22 \mathrm{~mm}$ cyst (Figure 1 ) which were shown to be TSC-associated RCC with clear margins pT1a (UICC, TNM 8th Ed). These tumour cells showed abundant clear cytoplasm with a branched elongated arrangement which was encircled in dense smooth muscle stroma (Figure 2). The ISUP nuclear grade was 2 with no sarcomatoid or rhabdoid change, Leibovich score was 0 (low risk).

\section{Literature Review}


Tuberous Sclerosis Complex is an autosomal dominant genetic disorder arising from inactivating mutations of either TSC1 (on chromosome 9q34.3) or TSC2 (on chromosome 16p13.3) which encode for hamartin and tuberin respectively. Inactivation of these proteins which are thought to function as tumour suppressors, lead to hamartomatous lesions in multiple organs, frequently involving the kidney in $60-75 \%$ of cases, but also found in the brain, skin, heart, lungs and retina. ${ }^{1-3}$ Penetrance is variable so clinical signs may not be apparent. $60-70 \%$ of cases are sporadic mutations with no family history. ${ }^{4}$ The two most common renal manifestations of TSC are angiomyolipomas (AML) occurring with a frequency of $34-85 \%$ (which are significantly more common in females), and cysts, occurring in approximately $44 \%$ of cases. The onset of these renal abnormalities is usually present by adolescence with the average age of onset of AMLs and cysts around 9 years old. ${ }^{1}$ Renal lesions in TSC are infrequently symptomatic. It is thought less than $10 \%$ of TSC patients with renal lesions have required biopsy or nephrectomy or experience haemorrhagic episodes. ${ }^{1}$

Incidence and risk of renal cell carcinoma in TSC

Renal cell carcinoma is a rare finding in TSC, and the exact incidence is unknown. It has been found to occur in $4.2 \%$ of cases in a recent review of 170 patients with TSC. ${ }^{1}$ This is in comparison to an annual incidence rate of renal cell cancer of 19.3 per 100,000 of the UK population based on 2015 Office of National Statistics data..$^{5}$ One case series has shown an increased frequency of AML involvement in TSC2 patients (60\% vs $22 \%$ in TSC1 patients). $95.6 \%$ of the TSC2 patients had more than four AMLs whereas the majority of TSC1 patients only had one AML. This study concluded that although severe renal disease including RCC can occur in TSC1 mutations, this is more likely to occur with TSC2 mutation. ${ }^{1}$ However, as only one TSC1 patient and two TSC2 patients were found to have RCC, risk for renal cell cancer based on genotype is unclear. There is no strong evidence to suggest that TSC mutations increase susceptibility to renal cell carcinoma, and no consensus on whether variants of AML are capable of metastatic growth resembling carcinoma. ${ }^{1}$ Based on the findings of RCC in the paediatric population with TSC, it is though that these RCCs are still related to the 
underlying genetic abnormalities in TSC rather than incidental sporadic malignancies. ${ }^{4} \mathrm{~A}$ metaanalysis of 107 reported cases of RCC in TSC published between 1922 and 1993 showed no significant increased risk for RCC in TSC compared with the normal population based on simple comparative statistics. ${ }^{6}$

\section{Diagnosis of renal cell carcinoma in TSC}

Diagnosing renal cell carcinoma in TSC preoperatively is a challenge due to the difficulty in distinguishing fat-poor AML from RCC on imaging. Use of renal biopsy can cause vascular AMLs to haemorrhage and scatter malignant cells, and histology from biopsy can also be ambiguous. The decision to remove tumours with partial or radical nephrectomy is also difficult as they are predisposed to developing additional renal lesions in the future. ${ }^{1}$ Further understanding is needed of the malignant potential of AMLs and renal masses in TSC and how to determine when intervention is required.

\section{Histology subtypes of TSC associated RCC}

Morphological descriptions and classifications of RCC in TSC have shown large variation in the published case reports. The most commonly reported tumour type until recent reports is a classification of clear or conventional RCC (up to $60 \%$ ). Some cases have also reported the tumours as 'chromophobe-like' and as oncocytoma due to abundant granular cytoplasm. ${ }^{7}$ More recently, histological analysis has suggested that TSC associated RCC could be histologically distinct from all other renal carcinomas in the WHO classification system. ${ }^{7}$

In the Guo et al. series of 57 renal cell carcinoma cases from 18 patients aged 7 to 65 years, the tumour sizes for TSC-associated RCC ranged from $1 \mathrm{~mm}$ to $23 \mathrm{~mm} .{ }^{4}$ Three patterns of TSC-associated RCC were described in this review: 1) containing smooth muscle bundles which encircle islands of renal cell carcinoma, initially described as renal angiomyoadenomatous tumour (RAT) which is now thought to be analogous to Clear Cell Papillary Renal Cell Carcinoma; 2) Chromophobe RCC like; and 
3) granular eosinophilic morphology now described in the somatic setting as eosinophilic solid and cystic (ESC) renal cell carcinoma harbouring TSC mutations. Our case likely represents the first pattern of TSC-associated RCC. In addition, the literature suggests, compared with sporadic RCCs, TSC-associated RCC have unique clinicopathologic features including female predominance, younger age at diagnosis, multiplicity, association with AMLs and the three histological patterns as described above. $^{4}$

\section{Prognosis of TSC-associated RCC}

Follow-up of case reports in the literature suggest that TSC associated RCC have a more indolent course than sporadic RCC despite having a higher likelihood of presenting with multiple and bilateral RCCs at a younger age. ${ }^{4}$ In the Guo et al. case series, 57 RCCs from 13 female and 5 male patients were reported. 50\% (9/18) of these patients had multifocal TSC associated RCC, which was either synchronous or metachronous, and 5/18 had bilateral RCCs. 15 of the 18 patients with histological finding of TSC-associated RCC had median follow-up period of 36 months (range 6 to 198 months). None of the 15 patients had evidence of metastatic disease at follow up. This included one patient with a single microscopic focus of metastasis in a single lymph node who had no evidence of metastasis at 32 months follow-up after surgery. ${ }^{4}$ In the Rakowski et al. case series of 170 patients with TSC, of the four confirmed patients in this series with RCC, one had TSC1 mutation, two had TSC2 and one had not been genotyped. One patient with TSC2 mutation had renal cell carcinoma confirmed by biopsy and died at the age of 28 years. Another female patient who had a normal ultrasound aged 21 was found at routine ultrasound age 23 with a $4 \mathrm{~cm}$ solid mass suspicious for renal cell carcinoma. ${ }^{1}$ There has been a report of RCC in a TSC patient aged $2 .{ }^{8}$ An older case series by Bjornsson et al. examined 6 cases of TSC associated RCC, of which 4 cases died of metastatic disease within 1 month to 5 years after diagnosis. ${ }^{9}$ The tumour histology in these cases was described as 'anaplastic' or 'clear cell'. The remaining two patients had their tumours detected incidentally at an earlier stage. ${ }^{9}$ 


\section{Discussion}

RCC in TSC is a rare tumour in a rare condition. Diagnosis of RCC in TSC is difficult due to presence of multiple renal lesions, often AMLs in these patients and therefore biopsy is also difficult. Optimal surveillance protocol for renal imaging in TSC unknown. Retrospective studies are not reliable in estimating tumour growth rate and measurements of lesion size as they are affected by different imaging modalities used. ${ }^{1}$ However, it seems follow-up of TSC with renal imaging seems prudent. One recommendation from Rakowski et al. is for paediatric TSC patients to have a baseline renal ultrasound before age 5, and if results normal, follow up ultrasounds every 2 to 3 years. If AMLs or cysts are found yearly ultrasound should be performed. If the imaging results are suspicious for renal cell carcinoma, then MRI can be performed and follow up imaging at six-month intervals. ${ }^{1}$

\section{References}

1. Rakowski SK, Winterkorn EB, Paul E, et al. Renal manifestations of tuberous sclerosis complex: Incidence, prognosis, and predictive factors. Kidney Int 2006; 70: 1777-82.

2. Cook JA, Oliver K, Mueller RF, et al. A cross sectional study of renal involvement in tuberous sclerosis. J Med Genet 1996; 33: 480-4.

3. O'Callaghan FJ, Noakes MJ, Martyn CN, et al. An epidemiological study of renal pathology in tuberous sclerosis complex. BJU Int 2004; 94: 853-7.

4. Guo J, Tretiakova MS, Troxell ML, et al. Tuberous Sclerosis-associated Renal Cell Carcinoma: A Clinicopathologic Study of 57 Separate Carcinomas in 18 Patients. Am J Surg Pathol 2014; 38: 1457-67.

5. Cancer Research UK. Kidney Cancer Incidence Statistics, www.cancerresearchuk.org/healthprofessional/cancer-statistics/statistics-by-cancer-type/kidney-cancer (2015, accessed $14^{\text {th }}$ April 2019). 
6. Tello R, Blickman JG, Buonomo C, et al. Meta-analysis of the relationship between tuberous sclerosis complex and renal cell carcinoma. Eur J Radiol 1998; 27: 131-8.

7. Schreiner A, Daneshmand S, Bayne A, et al. Distinctive Morphology of Renal Cell Carcinomas in Tuberous Sclerosis. Int J Surg Pathol 2010; 18: 409-18.

8. Lendvay TS, Broecker B and Smith EA. Renal Cell Carcinoma in a 2-year-old Child With Tuberous Sclerosis. J Urol 2002; 168: 1131-2.

9. Bjornsson J, Short MP, Kwiatkowski DJ, et al. Tuberous sclerosis-associated renal cell carcinoma. Clinical, pathological, and genetic features. Am J Pathol 1996; 149: 1201-8. 
Figure Legends

Figure 1

Haemotoxylin and eosin staining of partial nephrectomy specimen showing solid nodule next to cyst (x1 magnification)

Figure 2

Haemotoxylin and eosin staining of partial nephrectomy specimen showing the clear cell tumour cells comprising the solid nodule seen in Figure 1 (x8 magnification). 


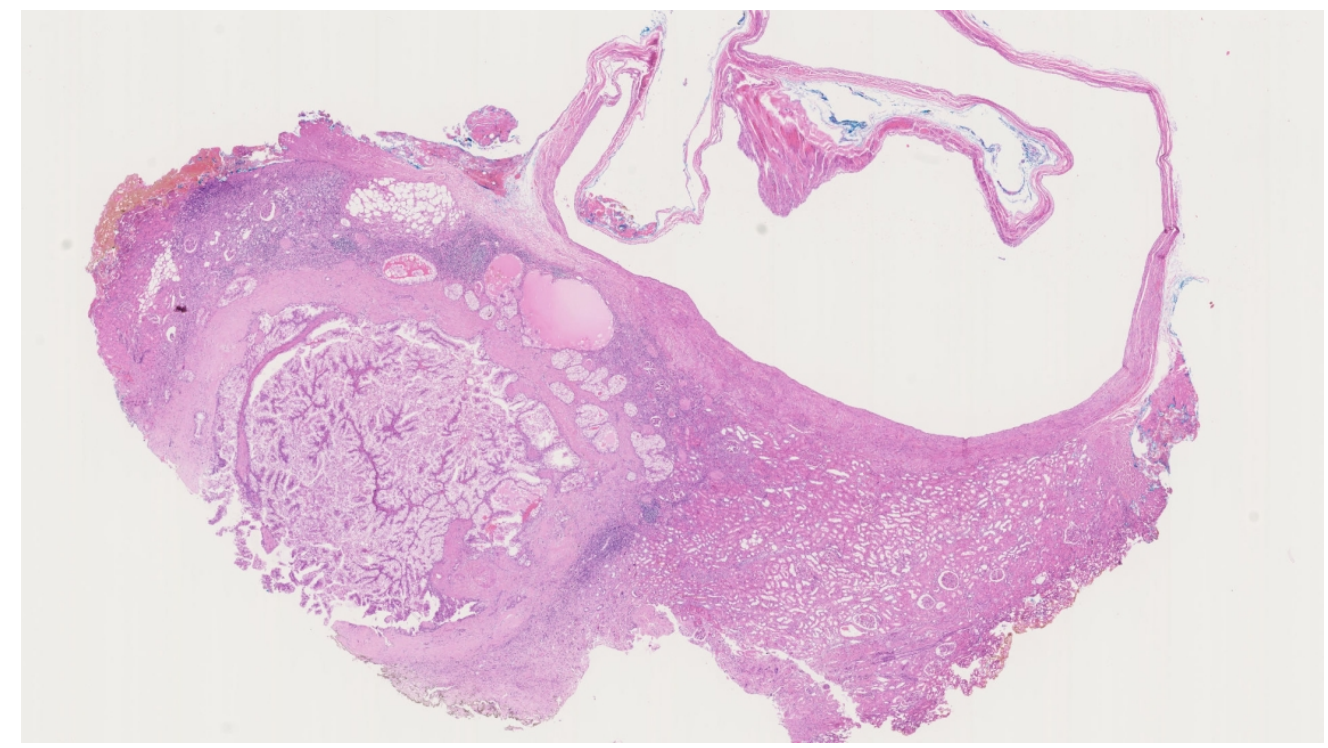

Figure 1

Haemotoxylin and eosin staining of partial nephrectomy specimen showing solid nodule next to cyst ( $x 1$ magnification).

$677 \times 381 \mathrm{~mm}(72 \times 72 \mathrm{DPI})$ 


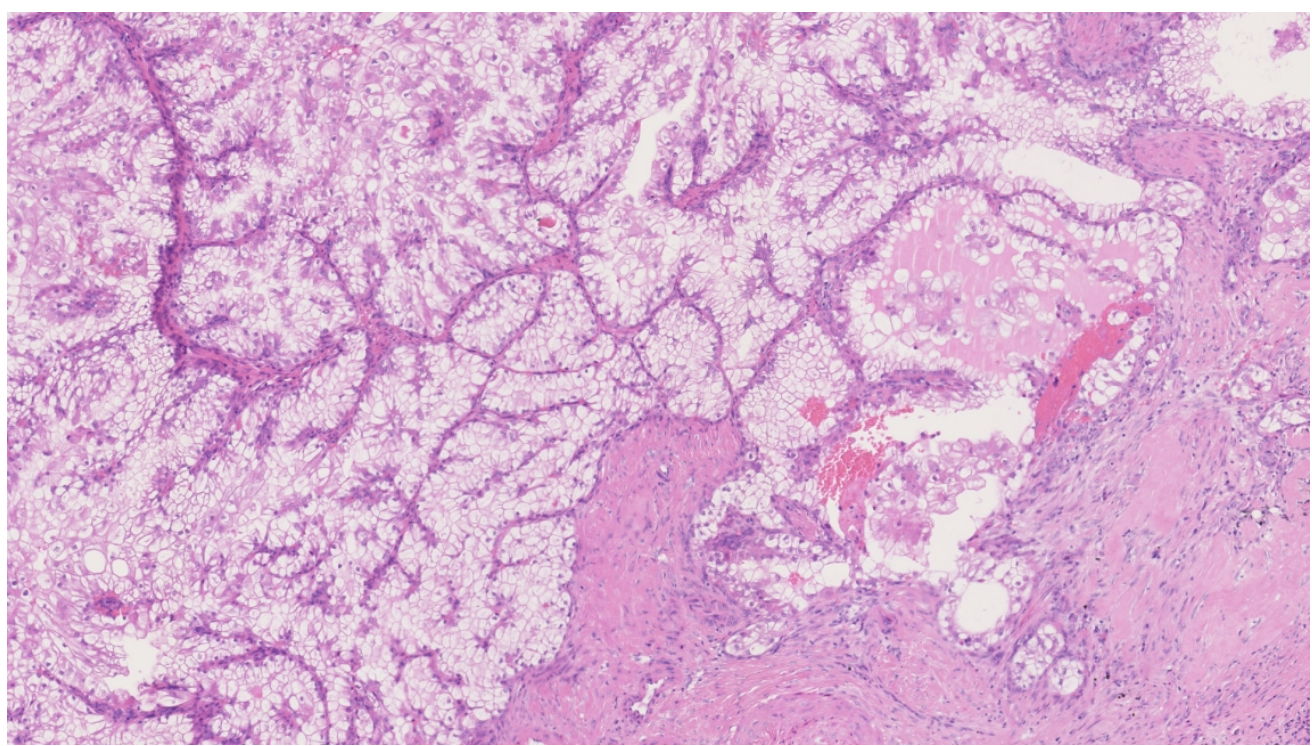

Figure 2

Haemotoxylin and eosin staining of partial nephrectomy specimen showing the clear cell tumour cells comprising the solid nodule seen in Figure 1 (x8 magnification).

$677 \times 381 \mathrm{~mm}(72 \times 72 \mathrm{DPI})$ 